\title{
Ethnic Minorities and the Politics of Identity in Iran
}

Elling, Rasmus Christian; Saleh, Alam

Published in:

Iranian Studies

DOI:

10.1080/00210862.2016.1118949

Publication date:

2016

Document version

Other version

Citation for published version (APA):

Elling, R. C., \& Saleh, A. (2016). Ethnic Minorities and the Politics of Identity in Iran. Iranian Studies, 49(1), 159171. https://doi.org/10.1080/00210862.2016.1118949 


\section{Iranian Studies}

\section{Ethnic Minorities and the Politics of Identity in Iran}

\section{Rasmus Christian Elling \& Alam Saleh}

To cite this article: Rasmus Christian Elling \& Alam Saleh (2015): Ethnic Minorities and the Politics of Identity in Iran, Iranian Studies, DOI: 10.1080/00210862.2016.1118949

To link to this article: http://dx.doi.org/10.1080/00210862.2016.1118949

册 Published online: 18 Dec 2015.

Submit your article to this journal 정

Џll Article views: 18

Q View related articles ¿

View Crossmark data ¿ 


\section{Review Essay}

\section{Ethnic Minorities and the Politics of Identity in Iran}

The present review essay is of a novel format: two authors working in the same field introduce each other's works, and then pose a number of questions to each other. The aim is to facilitate dialogue between scholars occupied with similar issues, theories, methods or problems, and to share their discussions with others. Here, Alam Saleh, Lecturer in Middle Eastern Politics, University of Exeter, and Rasmus Christian Elling, Assistant Professor of Iranian Studies, University of Copenhagen, introduce each other's recent books on ethnic minorities, identity and nationalism in postrevolution Iran. These introductions are then followed by questions and answers in relation to the topics covered by the books.

Ethnic Identity and the State in Iran, Alam Saleh, New York: Palgrave Macmillan, 2013, ISBN 978-1-137-31086-6, 233 pp. (hardback)

\section{Introduced by Rasmus Christian Elling}

In this, his first monograph, Saleh studies the contentious junction between ethnic diversity, geopolitics and security in Iran. He argues that the biggest single threat to Iran's domestic security, indeed to Iranian national identity, is the increasing discon- 


\section{Elling and Saleh}

tent amongst its ethnic minorities. Saleh's book seeks to gauge and analyze this threat by employing various research strategies.

Firstly, following a wide-ranging survey of theories on security, ethnic conflict, nationalism and identity, Saleh circles in on societal security and relative deprivation as the two main concepts, and Barry Buzan and Ted Gurr as the main thinkers through whose ideas he will explore the book's topics: ethnic inequality, collective identity crisis and the potential of ethnic conflict in Iran. Saleh thus aims to highlight an important dimension of Iranian politics that is often neglected in the international focus on Iran as a nuclear threat to "the West"-i.e. the Islamic Republic as a threat to itself. This self-threat, Saleh argues, has arisen from the way that the state authorities have consistently ignored regional discontent, consciously marginalized minorities and Persianized the non-Persian ethnic groups. Saleh's book in particular deals with the Arabs, Azeris, Baluch, Kurds and Turkmen-the five major ethnic groups that have seen the highest levels of politicization of ethnicity. The aim of the book is thus to shift from a narrow realist focus on Iran's relations with western powers to a more nuanced understanding of how internal societal factors impact on Tehran's foreign policy.

After having outlined the theoretical framework, Saleh investigates Iran's post-revolution security discourse. He discusses societal security with an emphasis on what he perceives as inherent contradictions of national and Islamic identity. Due to the Islamic Republic's ideology and policy, these contradictions have recently metastasized into an acute "national identity crisis." This crisis, combined with the state's mistreatment of its minorities, Saleh argues, has become a key challenge for the state that influences its policies at home and abroad.

Following these discussions, Saleh outlines the historical background of ethnic politics in Iran, shows how cultural diversity has been perceived by the state as a security challenge and how the use and abuse of ethnic sentiments inside Iran by foreign powers has made the state consider minorities a threat to territorial integrity. Saleh then examines the role of domestic hardliners in further exacerbating the tensions between center and periphery. The last two chapters draw on Saleh's own fieldwork in Iran and amongst Iranian diaspora, which include a number of qualitative interviews with members of different ethnic groups. These latter chapters further underscore the main arguments of the book: that the Islamic Republic has created an internal threat to itself by suppressing minority demands through assimilationist policies, by keeping segments of society in poverty and by assimilating minority communities into a majority Persian/Shiite culture. It is argued that ethnic minorities increasingly display resistance to the discriminatory state policies, demanding recognition, rights and autonomy.

The conclusion of Saleh's work is a dire warning: discontented ethnic minorities represent a fundamental challenge to the legitimacy and authority of the Islamic Republic, if not indeed a threat to a peaceful future for Iran. 
Minorities in Iran: Nationalism and Ethnicity after Khomeini, Rasmus Christian Elling. New York: Palgrave Macmillan, 2013, ISBN 978-0-230-11584-2, 267 pp. (hardback)

\section{Introduced by Alam Saleh}

Minorities in Iran provides a rare in-depth analysis of post-revolution Iran's national and ethnic identity questions. By problematizing questions of ethnicity, nationalism and identity, Rasmus Christian Elling aims in this monograph to answer the following question: who defines Iranians and the notion of "Iranian-ness"? In so doing, Elling aptly identifies the actors involved: minority elites, the Persian-centric nationalist elites and the state. The analysis of the book thus primarily focuses on these three actors' discursive-ideological points of view, particularly in post-Khomeini Iran. The book singles out the four major, transnational and politicized Iranian ethnic groups, namely the Azeris, Kurds, Arabs and Baluchis, and uses the histories of these communities to highlight changes in state/periphery relations in modern Iran.

After a theoretical and historical introduction, Elling critically examines Iran's ethnic diversity and dominant discourses on national identity, addressing paucities and biases in existing studies on Iran as well as the contentious politics of naming and labeling communities inside Iran. Chapter 1 thus contains important critique of Iranian Studies as a field as well as interesting general discussions on the social theory of identity. In chapter 2, Elling identifies the various historical, political and socio-economic causes of ethnic minority mobilization in post-revolution Iran. In doing so, he elaborates on the relationships of each ethnic group with the state, and then focuses on Khomeini and the post-Khomeini state's official views and policies towards ethnic diversity and nationalism. Elling concludes that ethnic minority mobilization in Iran is the result of state policies, under both the Pahlavi shahs and the Islamic Republic, but that the state's approach to this challenge has been shaped by historical and geo-political factors that must be taken into account.

Chapter 3 further explores the Islamic Republic's ideological discourse ("IslamoNationalism") and its attempt to address the issues of minorities and cultural diversity. This is highlighted through official statements and regime-sanctioned literature, as well as through semantic studies of the state's response to ethnically framed violence in Kurdistan, Khuzestan, Azerbaijan and Baluchistan in the period 2005-07. Elling particularly highlights the resurgence of nationalism in official rhetoric and the attempt to appease and attract minority populations while rejecting and oppressing radical minority activists.

In chapter 4, Elling critically assesses how Persian-centric nationalist elites perceive certain minorities as a threat in today's Iran, and in the process he questions the ontology of Iranian nationalism. He argues that elite perceptions of the minority issue have never been unitary but that they have nonetheless cemented a Persian-centric definition of Iranian-ness that has been detrimental to the country's minorities and their role in society and politics. He interestingly links this discussion through theories on ethnicity and identity, particularly those of Rogers Brubaker and Sinisa Malesevic, 
with the views expressed by minority activists ranging from the reformist and peaceful to the radical and separatist. In other words, the final chapters argue that the three actors-state, elite and minority activists-draw their approach from the same logics of essentialism, primordialism and groupism.

Elling's book ends on a positive note as it describes recent trends in Iranian academia as well as in popular discourse: trends that point towards a dawning realization amongst the majority of the minorities' plight.

\section{Q \& A}

\section{Rasmus Christian Elling's Questions for Alam Saleh}

Elling: A key theme for both of our books is identity, and in order to understand the minority issue in Iran, we both rely on a theoretical literature that places identity at the core of modern politics and social life. However, we seem to employ two different conceptualizations of identity. When questioning the success of the Islamic Republic in "protecting and establishing a coherent national identity" ( $p .45)$, when stating that mutual distrust between state and minorities "weakens Iran's national identity" ( $p .125)$ or when arguing that Tehran has "mismanage[d]... Iran's inherently confused historical identity" (p. 127), I sense that you understand identity as something that can objectively be "established," "protected," "managed"- and thus measured.

This appears to me to contradict the conceptualization employed in my own work of identity as a malleable, contextual and contingent self-understanding-indeed, identity as subjective social process rather than as an objective indicator. The reason for employing this conceptualization is that I think that by "measuring" identities as "weak" or "strong," we are in fact subscribing to the same skewed ontology that nationalism operates within. My question therefore is: is it Iranian national identity itself, which is under threat? Or is it rather certain powerful discourses attempting to define such "Iranian-ness" which are being questioned?

Saleh: Identity is not a given but rather is invented. Nevertheless, following constructivist approaches, when beliefs, identities or perceptions are constructed they become real and strong. People thus will kill or get killed for imagined identities, when they are strongly felt. Ethnic Identity and the State in Iran therefore does not argue that ethnonationalist sentiments in Iran are given facts. On the contrary, it argues that such ethno-nationalist perceptions are socio-historically constructed and imagined. Hence, identity is the result of a long and deep interaction between several, and often contradictory, variables and events in Iran's contemporary history.

In my book, I identify some of the themes and processes, which have had a profound impact in constructing and reconstructing Iran's national identity. In so doing, I have looked at, for instance, the role of Orientalists in Iran's nation-statebuilding processes, and how Iranian historians and elites borrowed and exploited 
Orientalist imaginaries to construct a coherent, homogenous Iranian identity based on Persian supremacy. This construct carried within it an anti-Other sentiment-i.e. the Persian-centric nationalism that was adopted by the Pahlavi shahs until the 1979 Islamic Revolution. The Islamic Republic, on the contrary, attempted to reconstruct Iran's national identity by adopting an ontologically different path: Islamism. By embracing the de-territorialized concept of Ummah, Ayatollah Khomeini undermined the idea of a geographically defined Iran. Khomeini argued that Islam is the only defining and unifying source of identity for Muslims regardless of their nationality, ethnicity and race. In this sense, Khomeini's ideology initially neglected Iran's internal diversity, particularly the ethnic and religious minorities.

Since the advent of the twentieth century, Iran has gone through three revolutions, two self-declarations of ethnic minority independence and a number of domestic uprisings, an eight-year war with Iraq, a revolution in technology and communication, globalization, many socio-political upheavals, and several major regional changes, all of which have deeply impacted on ethnic identities in Iran. Employing the concept of societal security (the dynamics in societies that perceive their identity as threatened) and relative deprivation theory (discrepancies between what people want and what they actually gain), I have explored the links between socio-historical events and their impact in increasing expressions of ethnic identity. However, transforming ethnic sentiments and frustrations into a major collective force against the state requires a politicization of ethnic identity that can mobilize societal groups. My book aims at investigating this process.

Identity confusion has led to the intensification of ethnic sentiments, which consequently causes societal insecurity in Iran. However, I frame the explanation for this in constructivist language. For instance, "politicized identity" indicates that ethnic sentiments in Iran do not necessarily represent the reality of their situation. In fact, I argue that feeling deprived may not suffice for the mobilization of ethnic groups. Ethnic elites, however, aim at politicizing and directing such a constructed sense of deprivation towards a targeting of the Other; in this case, the Persian and/ or Shiite state and society. Thus, whether minority grievances are grounded in reality or not, the important point is that the minorities perceive themselves as deprived.

Furthermore, globalization and the development of communication technology has provided ethnic groups with access to the internet, and to satellite TV channels programmed and broadcasted by their ethnic kin outside the country, as an alternative source of information to Tehran's state-sponsored media. Globalization has strengthened ethnic sentiments by increasing transnational interaction between ethnic groups on the both sides of the borders and beyond. The book argues that this consequently decreases ethnic groups' dependency on Tehran, and increases their ethnic identity awareness.

Finally, it is of utmost importance to remember that external actors have always been a vital challenge to Iran's national security by playing a role in influencing if not mobilizing ethnic groups in Iran. The fact that the Azeris, Kurds, Arabs, Baluch and Turkmen possess cross-border ethnic affinities increases the likelihood 
of foreign intervention, influence and internationalization of ethnic issues in Iran. The book thus moves beyond discussion of the internalization of Iran's ethnic issues and looks at its regional dynamics, including the creation of new states in the aftermath of the collapse of the Soviet Union, or the establishment of an autonomous Kurdistan region in Iraq.

In sum, numerous factors have shaped and reshaped ethnic identity construction in Iran. These internal, regional and international changes and dynamics affect Iran's national security, by undermining the cohesiveness of national identity and its territorial integrity. Such perceived threats preoccupy the state and the Persian elites' discourses, and their understanding of Iranian-ness.

Elling: In your book, you argue (correctly, in my opinion) that the ruling elites of modern Iran have consistently imagined Iranian national identity, or indeed "Iranian-ness" (irâniyyat), as a "uniquely Persian identity" (p. 42). You argue that when consolidating the modern Iranian nation-state, Reza Shah "defined national as denoting Persian nationality," and you show how "Persianism" has been used in Iranian nationalism as representative of "the authentic source of Iranian identity" (p. 58). I agree, but nonetheless I invite you to think out loud with me: if we agree that there is a policy of Persianization of ethnic minorities in Iran, then what factors into the underlying idea of "Persian-ness" and "Persianism"? What are the forces behind the idea?

Saleb: The process of nation-state building required Reza Shah to construct a narrative of common language, shared origins and collective historical memory amongst the Iranians. The new territorially framed national identity was based on Persian identity and the idea of Aryanism. The term national was conceived as denoting Persian-ness, a conceptualization that excluded the ethnic minorities. Drawing on Orientalist imaginaries, Iranian elite thinkers such as Ahmad Kasravi and Abdul Hussein Zarinkoob advocated Aryanism and Persian-ness as the origin and basis of Iran's national identity. With a lack of academic reasoning, historical knowledge and with little or no critical analysis, their Persianist approach in creating a national identity generated an antiOther sentiment hostile to particular minorities.

In my book, I argue that these policies remained unchanged in the aftermath of the 1979 revolution. The post-revolution state has instrumentally employed Shiism and Persianism to create a coherent national identity for Iranians. Persianists continued to produce a narrative on national unity that was based on the promotion of the Persian language to the exclusion of all other languages. Shiism was presented as a Persianized version of Islam, and along with Persian language, a unifying factor to bind together different ethnic groups in Iran. Thus, minorities perceive state policies as being constituted by a particular ideology, which seeks to define Iranian-ness as based on the superiority of a Persian/Shiite identity.

This ontologically conflicting juxtaposition-Islamism and nationalism or Persianism-led, consequently, to a greater complexity in self-understandings among Iranians. Nationalism invokes notions of the greatness of the pre-Islamic heritage as an authentic source of Iranian identity, and advocates a territorial patriotism, 
whereas Islamism advocates the universally framed concept of Ummah, which does not recognize borders, race and/or ethnic differences. In other words, the Islamic Republic has not had a coherent and definite national identity discourse. In fact, the Islamic Republic has pragmatically changed its discourse from Islamism to nationalism, or from nationalism to Islamism, or sometimes a mixture of them both. However, the impacts of such shifts on ethnic-religious minorities' self/other understanding remain evident. Statements given by interviewees in my book indicate that Tehran's Persianization policy is experienced by respondents as a key threat to their ethnic identity. Ethnic awareness of such discriminatory policies is widening the gap between the minorities and the state and thus has further intensified the politicization of ethnic identity.

Elling: My final question pertains to the scale of the problem we both outline in our books. We agree that ethnic minorities have returned to the political arena and are a force to be reckoned with. Where we differ is in that you perceive the minority issue as an existential "threat" to the Islamic Republic, and I refer to it as a "challenge."

Indeed, while we agree that relative deprivation is important in understanding the nature of minority discontent, I supplement it with the use of "raised expectations." I argue that despite revolutionary upheaval, bloody war, systematic discrimination and regional disparity, minorities have also experienced positive developments since the revolution. This includes significant improvements in infrastructure, health services, education and even some avenues for expressing minority cultures that were hitherto unthinkable. All of this, I argue, has raised expectations.

This is not meant to exonerate the Islamic Republic; as any reader of my book will acknowledge, I am keenly aware of all the shortcomings and inequalities generated by the political system. However, I feel that rather than explaining ethnic mobilization merely as a reaction against the Islamic Republic's failure in securing welfare, social justice and non-discriminatory equality, we should perhaps also understand the mobilization as a result of the massive socio-economic and cultural changes that Iran has undergone in the last three decades.

This brings us to the question of how to situate the ethnic minority movement within broader societal and political tendencies. I invite you to consider whether we should understand the growing movement for ethnic rights and recognition as part of a broader movement towards democracy. And, by extension, is the aim of the ethnic movement to overthrow the Islamic Republic?

Saleb: My book aims at deconstructing the state's securitization of the ethnic issue and how such policy has further politicized ethnic identities. By employing the concept of societal security, I question to what extent the Iranian state has been successful in creating a coherent national identity, and how ethnic groups perceive themselves today in relation to their Persian counterparts. Tehran's reluctance to acknowledge the multifaceted aspects of Iranians' identities has led to the lack of a coherent national identity. Instead, the state has employed two conflicting strategies to secure national identity; Persian hegemony and Shiite domination, both of 
which neglect, in their own ways, the ethno-religious minorities' societal demands. This, I argue, creates a challenge to Iran's national identity/security.

My book thus focuses on the implications of identity formation and its impact on Iran's national security. I argue that deprivation alone does not lead to ethnic conflict. The combination of a growing sense of deprivation and the politicization of ethnic identity, however, can lead to conflict. According to the findings of this book, Tehran has failed to meet ethnic expectations. Ethnic groups perceive their identity threatened and targeted by the Persianist policies. This has led to a rise in politicized identity awareness among ethnic minorities, and has widened the ideological gap between Iran's ethnic minorities and the state. This consequently may lead to societal insecurity, which undermines the legitimacy of the state.

According to Barry Buzan, societal security is about identity and concerns language, culture, religion, national identity and customs. Unlike social security that concerns the livelihood of people, societal security deals with situations in which societies perceive their identity as threatened. In other words, societal security is about identity, and groups' survival in terms of identity. If a majority society attempts to strengthen its own societal identity, the minority society may react with resistance, causing a societal security dilemma.

As I argue in my book, ethnic demands and the concept of security can be categorized into "objective" (a real/physical threat) or "subjective" (a perceived threat/nonphysical). Objective, tangible demands include employment, prosperity, health services and social security. Subjective demands, however, include, for example, those which refer to identity, ideology, religion and political issues. Although these demands often overlap, interact and reinforce each other, this book focuses on the subjective and societal aspect of ethnic demands in Iran. I argue that whether real or imagined, ethnic sentiments still impact on societal insecurity in Iran. Relative poverty in the minority regions can be instrumentally employed as a tool by ethnic elites to politicize their identities and to press demands that target the state as a source of threats to the survival of the minorities.

Societal insecurity primarily requires the development of discontent, the politicization of such discontent, and the intensification of frustrations, which ultimately causes an actualization of the anger in the form of collective mobilization. Ethnic minority members interviewed in my book expressed the belief that their ethnic identities are threatened by the state and/or the dominant Persian culture. Ethnic groups perceive their identity in danger when their language, customs and beliefs are targeted. However, they also express a broader perception of the "Persianization policy": not just cultural elimination but also systemic political marginalization, economic inequality, the imposition of poverty and the state's use of coercion. Neglected societal demands amongst the minorities, together with social expectations, create ethnic grievances, and when politicized, become a major potential source of threat to the state's national security.

In short, Tehran's reliance on the securitization of ethnic demands, and its method of dealing with the issue through coercive means, has further intensified the minority sense of deprivation. This intensification was expressed in the ethnic minority discon- 
tent of 2005-07, during which serious unrest occurred in Kurdistan, Khuzestan, Azerbaijan and Baluchistan. Although economic factors may coincide with ethnic societal demands, most of the ethnic minority members interviewed for my book perceived themselves as being politically marginalized, and complained about not being allowed to participate in local or national political decision-making. In other words, the centralization of the decision-making processes in Tehran, amongst many other factors, is perceived by the ethnic groups as being part of Tehran's intentional Persianization policy.

In short, real or perceived, threat or challenge, this book warns that ethnic identity in Iran has been politicized. Tehran's reluctance to address the rising ethnic expectations may lead to a greater frustration among the minorities. Other factors such as the role of mass communication technology, and regional dynamics and changes also play important roles in increasing ethnic expectations. This is particularly important since ethnic minorities in Iran are transnational and located along borders. Ethnic groups thus tend to look outwards to see their ethnic kin's situations in the neighboring countries and set their expectations accordingly, for instance vis-à-vis Kurds in Iraq or vis-à-vis the Azeris in the Republic of Azerbaijan. As discussed in my book, these external-internal dynamics frequently impact Tehran's domestic ethnic policies as well as its regional and foreign policy.

\section{Alam Saleh's questions for Rasmus Christian Elling}

Saleb: Your book Minorities in Iran: Nationalism and Ethnicity after Khomeini mainly deals with the important question of the relations between three actors: the state, the Persian-centric nationalist elite and the ethnic minority activists. It focuses on the divisions and differences between these three actors rather than within each of them. This may raise the following question: How about diversity and divisions within each ethnic group? Does the book perceive each group as having a coherent discursive approach towards the others? If not, what are the intra-ethnic diversities?

Elling: One of the main theoretical arguments of my book is that we need to treat "groupism" - that is, the essentialist grand narratives on ethnic and national identities-as a social rather than a sociological fact. Contrary to reductionist views on groups and identities, the social scientist must understand diversity as dynamics potentially involving more than one of numerous factors, including ethnic, linguistic, religious, sectarian, regional, tribal, socio-economic, gender and age. The sort of "overviews of ethnic demography" or "ethnic maps" that we often see in major western works of reference or in journalistic accounts, which divide Iranians into neat boxes of ethnic categorization tied up to particular geographic regions and with "statistics" or estimated numbers for each category, are fundamentally flawed. Such "ethnic" numbers and maps are entirely fictitious and misleading-we do not, in fact, have any large-scale data on how Iranians tend to categorize themselves. 
Nonetheless, we often see how this supposed knowledge is exploited for political ends, be it from Iranian nationalists seeking to belittle the minority issue, from minority activists blowing it out of proportions or from western powers seeking to abuse it towards their own goals in the region.

The "ethnic mapping" also neglects important historical, social dynamics that run counter to the logic of division on which the mapping takes shape. Iran has seen centuries of ethnic intermingling, exogamy, continuous in-migration $[\ldots]$, and the evolution of supra-ethnic or cosmopolitan notions of identity. This means that there are many Iranians who do not consider themselves to belong to any one category-they are simply "Iranians'." Minority activists may counter that these people are in fact "the Persians": the Persian-speaking Shiite majority that considers itself to constitute the essence of Iranian-ness, and through that position, marginalizes minority communities. However, I argue in my book that that is not a full explanation: there are many Iranians who simply will not identify in particular ethnic terms, and we need to take them into account when discussing diversity. I attempt in my work to deal with this through a concept of "elusive majority" and by examining the flexibility of markers such as "Iranian" and "Persian" as examples of the situated-ness of self-identification.

On the level of particular communities, there are numerous factors further complicating simplistic representations. For example, there are great differences between, say, an Azeri in Ardabil who speaks Azeri Turkic every day, and a Tehrani who descends from Azeri parents but may in fact have very little knowledge of Azeri language or culture. Another example could be the significant differences between a Shiite Kurd in Kermanshah and a Sunni Kurd in Marivan. These two may both understand themselves to be Kurds, but their ideas of their situation and identity may differ considerably when we dig deeper than the label "Kurd." Regional, sub-regional and tribal belonging as well as gender, age and class play into ethnicity on different levels and in different ways. In other words, when dealing with ethnicity as a scholar, we need to question ethnic self-understandings in both majority and minority terms that represent communities, populations and nations as static, internally homogenous, externally bounded identities. Ethnicity is not a fixed marker revealing an unchanging, inner essence but a fluctuating marker that politicizes cultural difference.

The minority question in Iran is thus not simply about particular groups facing other groups, nor is ethnicity reducible to majority/minority or state/periphery relations; indeed, there are also historic tensions between some minority communities. Examples include scattered tensions between Kurds and Azeris, or between Dezfulis and Arabs in Khuzestan. This topic, however, is severely understudied, and although my book is the first attempt at a comprehensive study of ethnicity and nationalism in post-Khomeini Iran, it only scratches the surface. Ideally, we should see a wide, interdisciplinary field of study emerge.

Saleh: The transnational nature and geographic location of certain ethnic groups in Iran seems to increase the likelihood of foreign influence, manipulation or intervention. This is particularly important considering the influence of external actors on Iran's ethnic policies. 
How does your book help us in explaining such a regional security complex and its impact on Iran's domestic security discourses?

Elling: I believe that there are two dimensions to this question. On the one hand, there is the very real history of foreign powers' self-serving exploitation of discontent amongst certain communities on Iran's territorial periphery; and on the other hand, there is the instrumental exploitation of this historical fact by Iran's current ruling elites in order to counter minority and regional mobilization. In other words, there are certainly genuine concerns in the ruling elites and the broader population that foreign powers, both global and regional players, have, can and will interfere and seek to manipulate minorities in Iran. Belligerent strategies of divide-and-conquer or of sowing internal discord and thus weakening the Iranian state are evident in many spheres, including that of minorities. Numerous journalistic accounts have dealt with recent examples of this interference, including among Kurds and Baluchis.

However, it also seems clear that certain powers in Iran are intent on blowing the threat of foreign manipulation out of proportion. There are two reasons for this. Firstly, the foreign threat is used as an excuse to employ excessive force against ethnic minority activists in Iran, whether the activists in question are militant or peaceful, and whether they adhere to Iran's territorial integrity or are avowed separatists. With this excuse, the military, intelligence and political elites can criminalize any and all expressions of minority culture or regional aspirations deemed to cross the "red line" and unwritten rules. The ruling elites can brand any and all minority activists as separatists, fifth-columnists and traitors by claiming that their activism runs counter to national security. Needless to say, this securitization of the minority issue has had a grave detrimental impact on minority activism in Iran. It has forced numerous activists to work underground, in fear of their safety, and it has radicalized many activists who may, in desperation over their lack of freedom of expression, be attracted to extremist ideologies of ethnic chauvinism, sectarianism or separatism. In that sense, the securitization of the minority issue tends to produce the very enemies it was supposed to eliminate. Current President Hassan Rouhani has promised to put an end to this securitization of the minority issue, but it remains to be seen if he will and can live up to this promise.

Secondly, the foreign menace is also used by politicians as an excuse to dismiss ethnic minority grievances. The argument, ritualistically repeated in Iranian state media and official discourse, is that the minority discontent expressed through demonstrations, riots, attacks on military installations or in online media is merely the work of a handful of radicals living in exile where they are bankrolled by Iran's foes to create havoc and ruin the harmonious co-existence of Iranians. This argument belittles and derides the genuine discontent amongst certain minorities, and it distorts the reasons for unrest rather than explains them. This in turn further cements the feeling of alienation and marginalization.

Saleb: Your book aptly studies elite discourses in detail, focusing on how these discourses aim to construct a Self, be it the state elites, nationalist elites or minority elites. While I 
agree that each were able in some cases to mobilize their constituencies, there are however also some cases where they were not. During the Iran-Iraq war, for instance, Arabs in Khuzestan arguably remained loyal to Iran rather than shifting allegiance to the Iraqi, Arab side. To what extent do you think each of the three actors have been successful in shaping or mobilizing such identities in today's Iran? How do people respond to the discourses?

Elling: Again, I believe we need to discard the groupist terminology in order to answer this question. Certainly, by far the majority of Arabs in Khuzestan rejected Saddam Hussein's overtures before and during the Iran-Iraq war, and I believe that the majority of Arabs in Khuzestan are similarly rejecting the pan-Arabic and sectarian propaganda emanating from certain Arab countries in the Persian Gulf today. In other words, the Arabs of Khuzestan, when threatened with foreign military interference or with well-financed propaganda from the outside, will mostly reject and resist, and in the process, they may frame this resistance as a patriotic duty towards Iran. It is indeed my impression that many if not most of Khuzestan's Arabs strongly identify with Iran as a historical entity.

However, that does not mean that they cannot identify with other historical entities, traditions or identity discourses. Ethnicity is situational and contextual. In one context, an Arab from Khuzestan will define him or herself as Iranian; and in another context, he or she will self-define as Arab. For example, if a Khuzestani Arab does not feel that his or her culture and lived reality is reflected in Iranian state media, he or she may switch to a foreign Arabic-language satellite station on the TV set. In the long run, such choices may strengthen the self-identification as Arab. However, the same person may also have to, depending on the context, define him or herself in regional terms, say as Ahwazi or Khorramshahri or Shadegani; perhaps in tribal or clan terms, depending on the situation; and obviously, he or she will often have to relate to his or her gender, class and age identity.

All of these factors are contingent, and despite the claims of both Iranian nationalists and local ethnic minority dissidents, no factor is unchangeable, overriding or fixed in time and space. In that sense, certain discourses may "succeed" in some cases, but will not necessarily succeed in other cases. That Arabs in Khuzestan resisted the Iraqi invasion with patriotic fervor does not mean that many Arabs today are not disillusioned with the Iranian state and its ruling elites. In fact, the two are directly connected: Arabs are frustrated by the fact that after having paid a huge price during the Iran-Iraq war, and while they live in Iran's most resource-rich region, most Arabs today are nonetheless suffering under unbearable socio-economic conditions, extreme pollution and systemic discrimination. When the explanation for this suffering is framed in ethnic terms, it will resonate with certain segments of the Arab communities, while the discourse of the state that stresses perennial multi-ethnic harmony, Muslim fraternity and the meta-historical inevitability of national unity may fail to convince.

What is interesting is that ethnicity has been quite neglected in Iranian Studies. Save for the tremendous efforts of anthropologists in understanding nomadic tribes 
in pre-revolution Iran, and for a handful of articles that have criticized Persian-centrism, there is a severe paucity of research. Often, scholars merely mention in passing that a very considerable segment of Iran's population defines itself in terms other than the stereotypical, Persian-speaking Shiite national Self. That is a shame, because it is perceived by those not represented in the mainstream history-writing as deliberate discrimination and marginalization. It is now time to break the silence on contentious aspects of ethnic diversity in Iran, and I believe that the two works discussed here are the first serious attempts at doing exactly that. I hope that our fellow scholars will join us in the discussion, and that it will become less sensitive for scholars and less dangerous for their informants to engage in exchange and debate on this issue. It is long overdue.

\section{Selected Publications}

Elling, Rasmus Christian. "Matters of Authenticity: Nationalism, Islam and Ethnic Diversity in Iran." In Iran: From Theocracy to the Green Movement, edited by Negin Nabavi, 79-99. New York: Palgrave Macmillan, 2012.

Elling, Rasmus Christian. Minorities in Iran: Nationalism and Ethnicity in Iran after Khomeini. New York: Palgrave Macmillan, 2013.

Elling, Rasmus Christian. "Tribal Hands and Minority Votes: Ethnicity, Regionalism and Elections in Iran." Ethnic and Racial Studies 38, no. 14 (2015): 2534-2550.

Saleh, Alam and Shahi, Afshin. (2015) 'Andalusiasation: Is Iran on the Trajectory of De-Islamisation?'. British Journal of Middle Eastern Studies. 42 (4), pp. 500-519.

Saleh, Alam and Worrall, James. (2015) 'Between Darius and Khomeini: Exploring Iran's Identity Problematique', National Identities. 17 (1), pp. 73-97.

Saleh, Alam. "Iran's National Identity Problematic." Sfera Politicii 4, no. 170 (2012): 50-59.

Saleh, Alam. "Relative Deprivation Theory, Nationalism, Ethnicity and Identity Conflicts." International Geopolitics Quarterly 8, no. 4 (2013): 156-174.

Saleh, Alam. Ethnic Identity and the State in Iran. New York: Palgrave Macmillan, 2013.

Rasmus Christian Elling

Assistant Professor, University of Copenhagen

(C) 2015, Rasmus Christian Elling

Alam Saleh

Lecturer in Middle Eastern Politics

Institute of Arab and Islamic Studies, University of Exeter

(C) 2015, Alam Saleh

http://dx.doi.org/10.1080/00210862.2016.1118949 